\title{
Fuzzy neural System Model for Online Learning Styles Identification, as an Adaptive Hybrid E- Learning System Architecture Component
}

\author{
L. Alfaro, Dr. ${ }^{1}$, C. Rivera, Mg. ${ }^{1}$, J. Luna-Urquizo ${ }^{1}$, E. Castañeda, Dr. ${ }^{1}$, and F. Fialho, Dr. ${ }^{2}$ \\ ${ }^{1}$ Universidad Nacional de San Agustín, Perú, casas@unsa.edu.pe, crivera@unsa.edu.pe,jlunau@unsa.edu.pe, \\ elisac@unsa.edu.pe \\ ${ }^{2}$ Universidade Federal de Santa Catarina, Brazil,fapfialho@gmail.com
}

\begin{abstract}
In the present work, we present a Fuzzy Neural System Model for online identification of Learning Styles which gives support for contents personalization. The model was developed to serve as a component for an Adaptive Hybrid ELearning System Architecture, which focus on a high degree of customization and content adaptation. We proposal a Hybrid System model, in which techniques of Neural Networks, Fuzzy Logic and Case Based Reasoning are incorporated into the multiagent system. Finally, the authors present the architecture of the Fuzzy Neural System model, the results of the analysis of the model validation tests establishing conclusions and recommendations.
\end{abstract}

Keywords - Hybrid architecture, e-Learning, Multiagent Systems, Adaptive Systems, Artificial Neural Networks, Fuzzy Logic, Fuzzy Neural Systems.

\section{INTRODUCTION}

The diversity and heterogeneity of the resources available in the education network, new trends in methodologies and teaching/learning tools, and the current needs of taking particular users characteristics into consideration, make it essential to have virtual learning environments that have characteristics of adaptation and personalization of content, use of virtual assistants, among others.

In this context, Multiagent Systems have proven to be one of the Artificial Intelligence techniques with the greatest potential in this field, since they allow modeling student characteristics facilitating tasks such as searching for information and content, as well as incorporating characteristics of Machine Learning.

Section 2 shows a systematic research and state of art, as well as the theoretical foundation of the concepts and approaches used in the design of the architecture. Section 3A describe a model of Knowledge representation, associated with the Adaptive Virtual Courses. Section 3B presents a proposed Multiagent Adaptive e-Learning system architecture, and Section 3C describe a Neural Fuzzy system for online identification of learning styles, which is one of the main components of the multi-agent system, which was developed and validated, as well as a brief description of other components that are in current development process.

Digital Object Identifier (DOI): http://dx.doi.org/10.18687/LACCEI2018.1.1.253 ISBN: 978-0-9993443-1-6 ISSN: $2414-6390$

\section{THEORETICAL FRAMEWORK}

\section{A. Agents and multi-agent systems}

According to Kasap [1], the existence of real-time applications such as online games, human-computer interfaces, collaborative learning environments, etc., shows the relevance of approaches based on multiagent systems. We are able to speak of intelligent virtual agents with autonomy, personality, power of decision, dynamism, among others.

There are different approaches to implement learning mechanisms in agents, including: reinforcement learning, Márkov decision chains, exploration strategies, evolutionary computation, among others [2]. For Corkill [3], one of the main challenges is to model communications between agents, their behavior and interactions, so the implementation of multiagent systems, such as the one proposed, is based on the use of ontologies [4].

\section{B. e-Learning Platforms and Agents}

According to C. Rivera, J. Luna, L. Alfaro and F. Fialho [5], the best way to implement e-Learning platforms that can integrate different types of actors, ability to manage heterogeneous resources, and personalization of content, is through methodologies based on intelligent agents. J. Herrera and L. Alfaro [6], propose the use of Multiagent systems, combined with other techniques of artificial intelligence, such as Case Based Reasoning, Genetic Algorithms and others, embedded in an intelligent e-Learning system, with the purpose that each resource, activity and educational service is flexible and adapts to the learning style of each student (personalized model of the student) and encourages collaborative learning online.

Additionally, A. Garro and L. Palopoli [7], propose the use of XML for the management of ontologies, which allows (i) to assist tutors in the definition of roles, competencies and associated knowledge (ii) to manage the map of required competencies; (iii) measure competition gaps in human resources; (iv) support the participant to fill their competence gaps in relation to their functions.

Some approaches on the use of agents in e-Learning systems are: based on learning styles [8], collaborative learning techniques, personalization of content with hybrid

16 $^{\text {th }}$ LACCEI International Multi-Conference for Engineering, Education, and Technology: "Innovation in Education and Inclusion", 19-21 July 2018, Lima, Peru. 
approaches and recommendation strategies [9], [10], personalization of learning objects in web 3.0 environments [11], learning the cognitive process of the user through neural networks, personalized accompaniment for meaningful learning supported by an intelligent virtual assistant [12], among others.

C. Methodologies for the development of intelligent multiagent systems

There are different methodologies for the development of Multiagent systems, such as those proposed by Wooldridge [13], Caire [14], Huget [15], and Gomez-Sanz [16], as well as some general architectures for the implementation of agents, such as the one presented by Vidal [17]. In the present work, the work of Brusilovsky [18] has been taken as reference, where an architecture for distributed learning is defined, called Knowledge Tree; and the use of a blackboard agent for the implementation of adaptive e-learning systems, proposed by Hammani [19].

There is also a set of techniques in several areas, which can be applied to the improvement of the proposed models, such as Case-Based Reasoning techniques applied to the evaluation and selection of projects, according to the characteristics of the audience, use of Neural Networks for improvement the content customization, adaptation of contents according to the characteristics of the audience and context of the students, etc.

\section{Learning Styles and Neural Networks}

According to J. Lo and P. Shu [20], most researchers in the area agree that carrying out the teaching process considering learning styles can tremendously increase the effectiveness and efficiency of learning. Adaptive Hypermedia technology represents an effective strategy to solve many of the learning problems involved in online platforms [18]. The idea behind this technology focuses on adapting the contents of a course, according to the particular characteristics of a user. According to Carver [21], any web-based learning system should also include information about users to optimally adapt instructional materials, with the identification of learning styles being a key aspect.

The problem of recognizing individual characteristics of a user involves the classification of a number of categories from a potentially infinite number of entries [20], which is why many researchers point to neural networks as the best approach to solve this problem due to the following advantages of this technique:

(i) Ability to recognize patterns from inaccurate or poorly understood data

(ii) Ability to generalize and learn from specific examples

(iii) Ability to quickly update with additional parameters

(iv) Speed of execution, which makes it ideal for applications in real time.
According to these premises, various proposals have been developed with different approaches. Some examples of this are: use of competitive Neural Networks to find users with similar interests and attitudes based on questionnaire answers [22], the integration of Neural Networks with Case Based Reasoning, to recognize the intentions of the users during their navigation [23], Multilayer Feed-Forward Neural Networks and Conceptual Maps for observing the user's navigational behavior [20], Intelligent Diffuse Models for the characterization of student profiles [26], Fuzzy Cognitive Maps for learner's style and profile recognition [27], Performance Evaluation of Learning Styles Based on Fuzzy Logic Inference System [28], among others.

\section{Proposal OF Multi-Agent System Model For ADAPTIVE E-LEARNING}

\section{A. Model of knowledge representation}

The static technology we have conceived so far tends to disappear, giving way to a new paradigm where users have a wide range of interfaces and devices to communicate with information systems, and where the context plays an extremely important role. To address these needs, emerging technologies and approaches emerge as intelligent software agents, wireless devices, adaptive and personalized information retrievers to create computerized recommendation models.

For the implementation of the knowledge representation scheme, we selected the model proposed by F. Arias [24], associated with the Adaptive Virtual Courses - CVA, which is based on the following concepts:

- Adaptive Virtual Course (AVC): study on a subject, developed with a conceptual unit. It represents a framework in which the protagonists (teachers, monitors and students) can interact with each other instantaneously, at any time and from anywhere.

- Basic Unit of Learning (BUL): can be seen as a subdivision of the courses, similar to chapters of a book. A UBA cannot be evaluated in a single session of a course.

- Subject: Each unit of content in which a study program or a textbook is divided.

- Learning Object (LO): digital educational resource which is described from metadata, a feature that allows its reuse, migration, recovery and recommendation.

- Evaluation: mechanism through which the performance of a student within a AVC is evaluated, allowing student to advance in the learning process by means of the habilitation of new educational contents.

- Educational Objective (EO): demonstrate the teacher's intention about what students should learn. An educational objective is achieved by carrying out educational activities and the corresponding evaluations. 


\section{B. Agent Architecture}

The hybrid architecture proposed by the authors is shown in Figure 01.

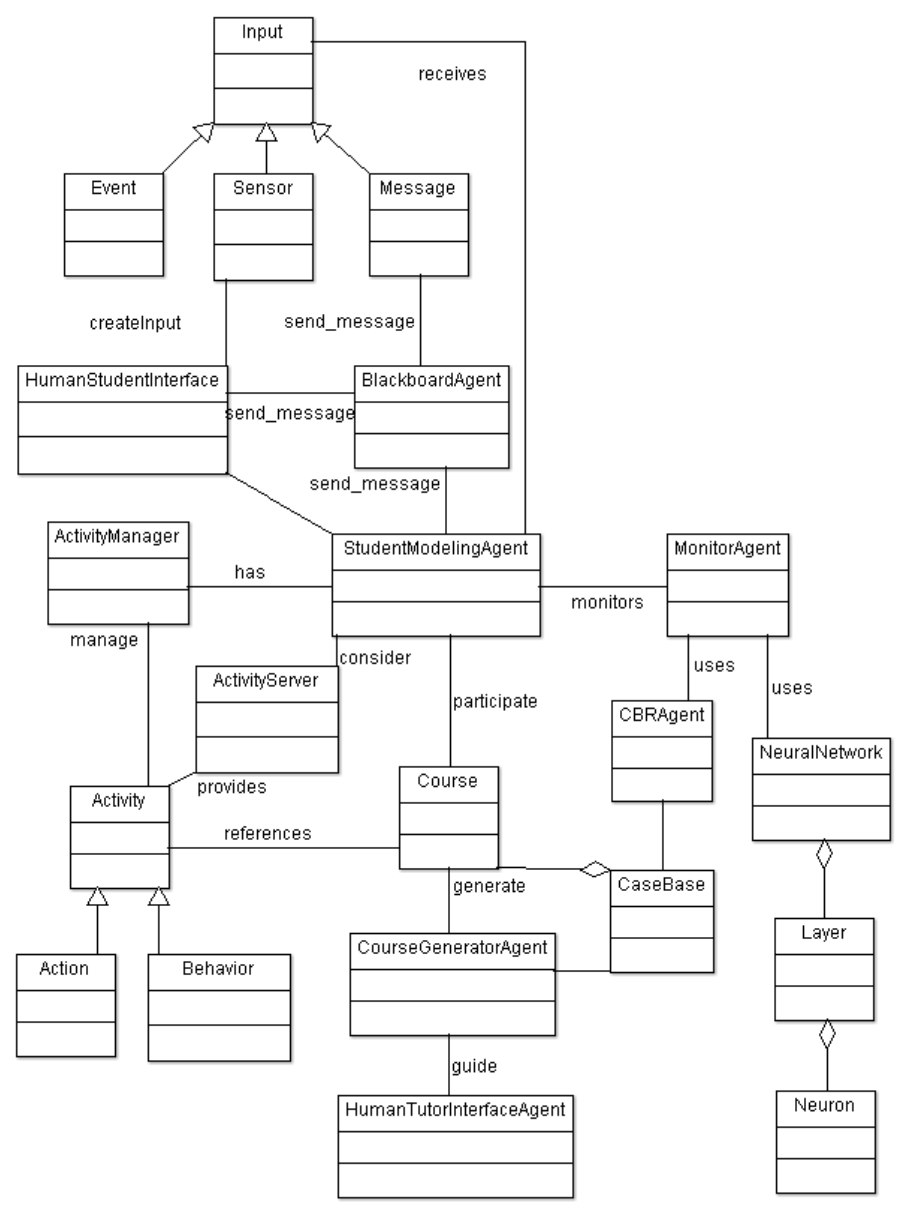

Fig. 1 Hybrid Architecture Proposed.

As part of the architecture, a StudentModelingAgent is proposed, which represents the student's needs and objectives in the learning process:

(i) collects data about student performance throughout each course and activity that he develops.

(ii) provides information about the student to the tools for adapting and personalizing content.

(iii) handles the student's reminders, scheduled by him or by the courses in which he is enrolled.

The StudentModelingAgent, coordinates actions with the MonitorAgent, which monitors the resources and activities available for a given course, requests information from the student, and executes techniques of Case Based Reasoning and Neural Networks, to identify the learning style and the preferences of the user, whose development, implementation, testing and validation is reported in section 3.C of this article; as well as selecting the most appropriate content for him, and finally, he sends information about what he has learned about the student to update the knowledge of the
StudentModelingAgent. This agent also coordinates actions with the Agent Course, whose functionalities are based on the proposal of F. Arias [24].

The BlackboardAgent is an agent that centralizes communications, through a shared data structure. This agent allows the temporary storage of information that is useful for a certain group of agents, and takes the task of distributing the messages to the interested agents. It has a notification mechanism in order to provide the availability of a shared resource.

The CouseGeneratorAgent is responsible for consolidating teacher requirements, through the interface agent HumanTutorInterfaceAgent, and generating the structure of the course, with the support of a case-based reasoning mechanism. To do so, consult the ActivityServer and reference the activities and contents. suitable for the generated course, thus favoring reuse.

The ActivityManager is a reactive agent whose purpose is to manage the student queue of tasks or activities, i.e. for each input received by the student, he selects an activity to execute or a content to be used, which allows him to carry out the objective raised. For the selection of activities, the agent consults the ActivityServer component, which is basically a repository specialized in some topic, highly interactive, that stores activities proposed by teachers or specialists at different times and courses. This component favors the reuse of activities, contents and learning objects. The activities can be actions to be learned, resources to be used, simple or nuclear actions, repetitive actions in time or set of actions to be executed in the long term.

Additionally, there are two interface agents, the HumanStudentInterface, which allows the student to interact directly with his StudentModelingAgent, for example, to establish personalized reminders, program specific activities, or provide information through the available sensors, and the HumanTutorInterfaceAgent, which allows you to configure the parameters for the generation of a course, obtain reports, among others. All interactions with other agents and through interfaces with real users are represented through entries.

\section{Online identification of learning style using a Neural Fuzzy system}

This module is based on the previous work of the authors [25], for the collection of test data, we applied the learning styles questionnaire proposed by Honey [7], to a group of 70 higher education students of the National University of SanAgustín during the first semester of the year 2017, so that the Learning Style of each student was known in advance according to a traditional method.

A modified version of the open source Moodle platform was used, applying the following adaptations:

- A list of categories or types of resources to be used within the course was defined, establishing 20 categories. 
- Fuzzy sets were defined, to correlate each category or type of resource with each learning style proposed by Honey.

- A model course was established, ensuring that each content has, in most cases, alternative presentations corresponding to types of resources with fuzzy sets without intersections.

- The source code of the platform was modified, in order to save a log with the selections (clicks) made by each student, which represent the user's behavior, according to the previously established categories.

In this way, it was possible to obtain the inputs and outputs of the proposed model, dividing the data into two sets of the same cardinality (a training set and a test set). For the division of the data, the criterion of representativeness of learning styles was used, so each sub-set there is approximately the same proportion of learning styles with respect to the total set.

Due to the amount of resource categories, and the fact that some content or activities within the platform, could not always have alternative presentations with non-close learning styles, the initial tests using all of the user's clicks or selections were not satisfactory, since some sets of inputs presented a lot of noise and made it difficult to train the Neural Network or distorted the output.

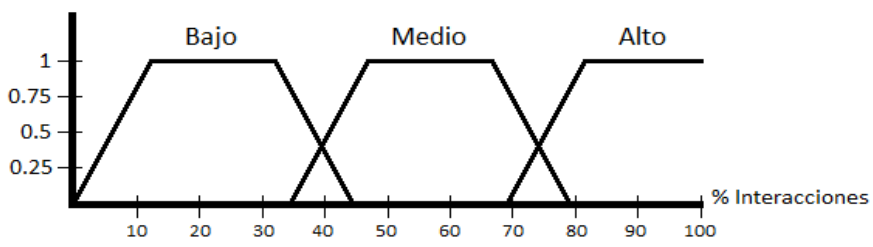

Fig. 2 Preference of a user for a certain category of resources, according to the percentage of interactions in the e-Learning platform.

To solve this problem, it was decided to define a second group of fuzzy sets, which would better categorize a user's preference for a certain category of resources, according to the percentage of interactions in each category, as shown in Figure 02. This fuzzification of the data obtained through the log of the e-Learning platform has been considered as a stage of preprocessing of the entries.

For example, a user whose learning style is predominantly defined as "active" may have selected a few times resources primarily related to the "reflexive" or "theoretical" learning styles, because the information contained in these resources was indispensable for other activities within the course or the evaluation of the same, although they were not of their preference, nevertheless these "few" interactions should not be determinant for the application of the model.

As a central component, a Back-Propagation Neural Network was used, composed of an input layer, a hidden layer, with sigmoidal activation function and an output layer, as shown in Figure 03. The objective of the Neural Network model is to identify the learning style of a specific individual, based on their interactions and behavior, within an e-Learning platform.

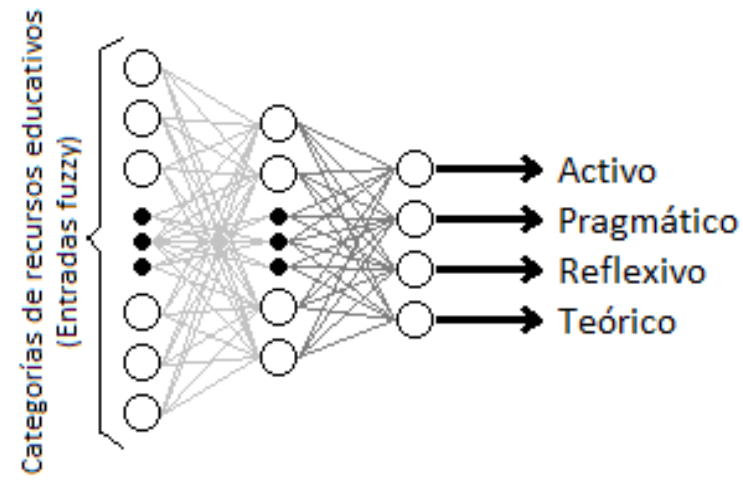

Fig. 3 Neural Network Architecture.

The input neurons represent the interactions of the users in the e-Learning platform, previously fuzzified, as was described in the pre-processing stage, for this reason 20 neurons have been considered in this layer, corresponding to each one of the previously defined resource categories.

The hidden layers provide the processing power of the Neural Network, and the number of neurons in the hidden layer directly affects the ability to learn from the Neural Network, however in the particular case proposed, tests were made with different numbers of neurons in the Neuronal Network. the hidden layer, according to some of the most recommended approaches in the literature, however, good results were not obtained due to the amount of noise in the inputs, so it was decided to pre-process the inputs.

The output layer consists of four output neurons, corresponding to the four learning styles proposed by Honey, indicating the predominant learning style for each student.

It is important to note the difficulty of identifying a student's learning style in a single week or learning session, since their interactions with the platform may vary according to the topic developed, the type of resources available, the availability of time in a particular moment, among other factors, as shown in figure 04 for some model cases.

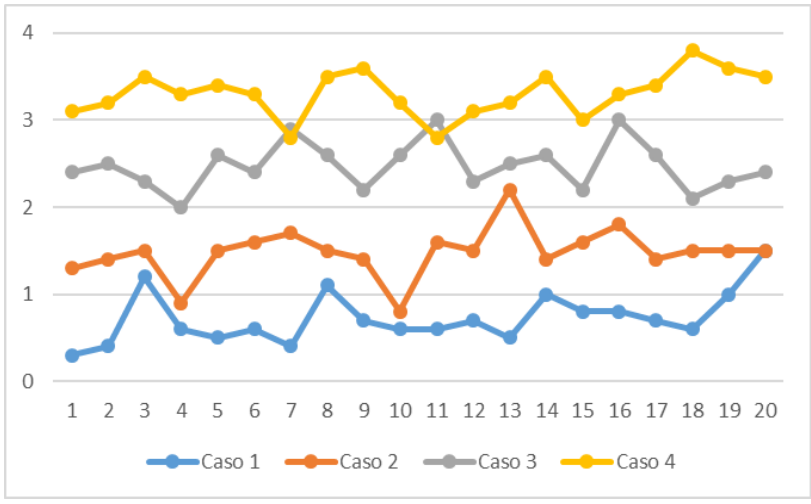

Fig. 4 Variations in the identification of the learning style according to specific sessions

16 $^{\text {th }}$ LACCEI International Multi-Conference for Engineering, Education, and Technology: "Innovation in Education and Inclusion", 19-21 July 2018, Lima, Peru. 
According to this approach, it would be necessary to identify the learning style during an introductory course such as the "Study Methodology", and then adapt the contents of the following courses. It is necessary to monitor and validate the relevance to that learning style each semester,

Taking data from student interactions and student test data (traditional method), we used half of the data as a training set and the other half as a test set to compare the results obtained with the Network Neuronal Under this approach, the neural network and the proposed model reached a $77 \%$ effectiveness or coincidences in the identification of the learning style with respect to the Honey test.

The importance of online detection of the learning style, is that using the modified version of the Moodle platform developed, the contents of each course will be personalized, based on each student's learning styles, as far as possible. the possible and the available resources for each category, which will also allow refining the results and validating the styles identified over time, which will make it possible to improve the efficiency of the teaching / learning process throughout the process, which it will be carried out and analyzed in subsequent works.

\section{CONCLUSIONS}

A Neural Fuzzy Model Architecture was proposed, whose input data were fuzzified in a preprocessing stage, which allowed the online identification of the learning styles, from the interaction of the students with the e-Learning platform, with the object to meet the demands of the HumanTutorinterfaceAgent, of the treatment of learning and thinking styles, to adapt to personal requirements.

The identification of learning styles cannot be based on a single learning session or user access, and may result in errors of interpretation of learning style, but must be made over several sessions to achieve refinement and adequate accuracy in the identification and Attention to the demands of the student's learning style.

This work was carried out in the context of the proposal of the authors of an SMA of e-Learning, adaptive that is sensitive to the context, which integrated the elements previously characterized, according to the methodologies of the literature reviewed, highlighting that the characteristics and functionalities of the different agents, were established considering the technological attributes and evolution of the contemporary demands, of the students and the resources they use, in the realization of their courses.

The use of Neural Networks associated with Fuzzy Logic, made it possible to propose a novel approach, for the resolution of a complex problem, in the line of research of eLearning platforms.

\section{REFERENCES}

[1] Z. Kasap \& N. Magnenat-Thalmann, "Intelligent virtual humans with autonomy and personality: State-of-the-art", Intelligent Decision Technologies, Vol. 1, No. 1, pp. 3-15, IOS Press, DOI: 10.3233/IDT2007-11-202, July 2007.

[2] N. Vlassis, "A Concise Introduction to Multiagent Systems and Distributed AI", Universiteit van Amsterdam, 2003.

[3] D. Corkill, "Software: Blackboard and Multi-Agent Systems \& the Future", In Proceedings of the International Lisp Conference, New York, New York, October 2003.

[4] A. Garro \& L. Palopoli, "An XML Multi-Agent System for E-learning and Skill Management", Agent Technologies, Infrastructures, Tools, and Applications for E-Services: NODe 2002 Agent-Related Workshops Erfurt, Springer Berlin Heidelberg, pp. 283-294, ISBN: 978-3-54036559-4, DOI: 10.1007/3-540-36559-1_21, Germany, 2003.

[5] C. Rivera \& J. Luna \& L. Alfaro \& F. Fialho "Meta-Model for a project based collaborative M-Learning system. An approach using intelligent pedagogical agents, case-based reasoning and automatic detection of learning and thinking styles", submitted to XLIII Conferencia Latinoamericana en Informática, 2017.

[6] L. Alfaro, \& J. Herrera, "Modelo de un Sistema de Gestión de Aprendizaje Inteligente Híbrido: Un enfoque basado en estilos de aprendizaje", Editorial Académica Española, 268 pages, ISBN-10: 384176570X, ISBN-13: 978-3841765703, January, 2017.

[7] A. Garro \& L. Palopoli, "An XML Multi-Agent System for E-learning and Skill Management", Agent Technologies, Infrastructures, Tools, and Applications for E-Services: NODe 2002 Agent-Related Workshops Erfurt, Springer Berlin Heidelberg, pp. 283-294, ISBN: 978-3-54036559-4, DOI: 10.1007/3-540-36559-1_21, Germany, 2003.

[8] C. Wolf, "iWeaver: Towards 'Learning Style'-based e-Learning", in Computer Science Education, Australasian Computing Education Conference (ACE2003), Conferences in Research and Practice in Information Technology, Vol. 20, Australia, 2002.

[9] A. Klašnja-Milićević \& B. Vesin \& M. Ivanović \& Z. Budimac, "ELearning personalization based on hybrid recommendation strategy and learning style identification", Computers \& Education, Volume 56, Issue 3, April 2011, Pages 885-899, ISSN 0360-1315, DOI 10.1016/j.compedu.2010.11.001.

[10] C. Peña, "Intelligent Agents to improve adaptivity in a web-based learning environment", PhD. Thesis, Universidad de Girona - España, ISBN 84-688-6950-3, 2004.

[11] E. Kurilovas \& S. Kubilinskiene \& V. Dagiene, "Web 3.0 - Based personalization of learning objects in virtual environments", Elsevier, Computer in human behavior, 2013.

[12] V. Rissoli, "Uma proposta metodológica de acompanhamento personalizado para aprendizagem significativa apoiada por um assistente virtual de ensino inteligente", Tesis de Doctorado, Universidade Federal do Rio Grande do Sul. Centro de Estudos Interdisciplinares em Novas Tecnologias da Educação, Brasil, 2007.

[13] M. Wooldridge \& N. Jennings \& D. Kinny, "The Gaia Methodology for agent-oriented analysis and Design", International Journal of Autonomous agents and Multi-agent systems, Vol. 3, No. 3, pp. 285$312,2000$.

[14] G. Caire \& P. Chainho \& R. Evans \& F. Garijo \& J. Gomez-Sanz \& P. Kearney \& F. Leal \& P. Massonet \& J. Pavon \& J. Stark, "Methodology for Agent Oriented Software Engineering", EUROSCOM Project P907, 2001.

[15] M.P. Huget, "Agent UML Class Diagrams Revisited", Proceedings of Agent Technology and software engineering, 2002.

[16] J. Gomez-Sanz \& R. Fuentes, "Agent oriented system engineering with INGENIAS", Proceedings of the 4th Iberoamerican Workshop on MultiAgent Systems, 2002.

[17] J. Vidal \& P. Buhler, "A Generic Agent Architecture for Multiagent Systems", USC CSCE TR-2002-011, University of South Carolina, 2002.

[18] P. Brusilovsky, "KnowledgeTree: A Distributed Architecture for Adaptive E-Learning", Proceedings of the 13th international World

16 $^{\text {th }}$ LACCEI International Multi-Conference for Engineering, Education, and Technology: "Innovation in Education and Inclusion", 19-21 July 2018, Lima, Peru. 
Wide Web conference (ACM), pp. 104-113, ISBN 1-58113-912-8,DOI 10.1145/1013367.1013386, New York, USA, 2004.

[19] S. Hammami \& H. Mathkour \& E. Al-Mosallam, "A multi-agent architecture for adaptive E-learning systems using a blackboard agent," 2009 2nd IEEE International Conference on Computer Science and Information Technology, Beijing, 2009, pp. 184-188. doi: 10.1109/ICCSIT.2009.5234741

[20] J. Lo \& P. Shu, "Identification of learning styles online by observing learners' browsing behaviour through a neural network", British Journal of Educational Technology Vol. 36, No 1, pp. 43-55, Published by Blackwell Publishing, 2005.

[21] C. Carver, \& R. Howard, \& W. Lane. Enhancing student learning through hypermedia courseware and incorporation of student learning styles. IEEE Transactions on Education, 42, 1, 33-38. 1999.

[22] G. Castellano, \& A.M. Fanelli, \& T. Roselli, (2001). Mining categories of learners by a competitive neural network. Proceedings of the INNSIEEE International Joint Conference on Neural Networks (IJCNN '01), 945-950

[23] Micarrelli, A. \& Sciarrone, F. (1996). A hybrid architecture for the recognition of user interests during hypermedia navigation. IEEE International Conference on Systems, Man and Cybernetics, 2, 13701375.

[24] F. Arias, "Modelo multi-agente para la planificación instruccional y selección de contenidos en cursos virtuales adaptativos". Tesis de Maestría. Universidad Nacional de Colombia.

[25] L. Alfaro, C. Rivera, J. Luna-Urquizo, E. Castañeda, F. Fialho. "Online Learning Styles Identification Model, Based On The Analysis Of User Interactions Within An E-Learning Platforms, Using Neural Networks And Fuzzy Logic" Submitted to International Conference on Communication, Management and Information Technology, 2018.

[26] Dongming X., Huaiqing W., Kaile S., "Intelligent Student Profiling with Fuzzy Models". Proceedings of the 35th Hawaii International Conference on System Sciences. DOI: 0-7695-1435-9/02, USA, 2002.

[27] Georgiou D., Makry D., "A Learner's Style and Profile Recognition via Fuzzy Cognitive Map". Proceedings of the IEEE International Conference on Advanced Learning Technologies (ICALT'04). DOI: 07695-2181-9/04, 2004.

[28] Ozdemir A., Alaybeyoglu A., Mulayim N., Filiz K., "Performance evaluation of learning styles based on fuzzy logic inference system". Computer Applications in Engineering Education, Vol 24, No. 6, pp. 853-865. DOI: https://doi.org/10.1002/cae.21754, 2016.

16 $^{\text {th }}$ LACCEI International Multi-Conference for Engineering, Education, and Technology: "Innovation in Education and Inclusion", 19-21 July 2018, Lima, Peru. 